\title{
Patient perspectives on fluticasone-vilanterol versus other corticosteroid combination products for the treatment of asthma
}

This article was published in the following Dove Press journal:

Patient Preference and Adherence

13 May 2016

Number of times this article has been viewed

\author{
Suzanne G Bollmeier \\ Theresa R Prosser \\ St Louis College of Pharmacy, \\ St Louis, MO, USA
}

Correspondence: Suzanne G Bollmeier St Louis College of Pharmacy, 4588 Parkview Place, St Louis, MO 63II0, USA

Tel +I 3 I 44468525

Fax + I 3/4 4468500

Email sbollmeier@stlcop.edu
Objective: Fluticasone furoate (FF), an inhaled corticosteroid (ICS), and vilanterol (VI), a long-acting beta ${ }_{2}$ receptor agonist (LABA), is a new combination used in an Ellipta ${ }^{\circledR}$ device. This article compares FF-VI to other ICS-LABA combinations available, particularly emphasizing product selection from the patient perspective.

Data sources: A PubMED and EMBASE search completed in October 2015 identified trials using the MeSH terms "fluticasone", "vilanterol", and "asthma". Additional information was gathered from references cited in the identified publications, the manufacturer, package insert, and ClinicalTrials.gov registry.

Study selection/data extraction: Preference was given to randomized controlled clinical trials. Animal trials, trials for COPD, and non-English sources were excluded.

Data synthesis: Seven efficacy trials of FF-VI in asthma were identified. Only one (24 weeks) trial compared FF-VI to another ICS-LABA combination (fluticasone propionate-salmeterol). Primary outcomes (usually lung function) and secondary outcomes (eg, quality of life and symptom scores) were comparable. In three FF-VI safety trials, the type and frequency of common adverse reactions (ie, thrush and dysphonia) were similar to those in clinical trials. Over $90 \%$ of subjects rated the Ellipta ${ }^{\circledR}$ device as "easy to use" and demonstrated correct device technique initially and at 4 weeks.

Conclusion: Individuals may have drug- and device-specific preferences that should be incorporated into therapeutic decision making. Limited data indicate that clinical and patient-oriented efficacy/safety outcomes of FF-VI are likely comparable to other available combinations for adults with asthma. Patient-friendly features include once-daily dosing, flexibility of dose timing, and design/ease of the use of the device. Additional larger and long-term comparative studies are needed to determine whether these features translate into greater efficacy, safety, patient preference, or adherence versus other ICS-LABA combinations. In the next few years, the availability of less expensive generic ICS-LABA products may strongly influence patient preference.

Keywords: Breo, fluticasone-vilanterol, Ellipta ${ }^{\circledR}$, patient preference, adherence, inhaled corticosteroid, respiratory devices, long acting beta receptor agonist

\section{Introduction}

Asthma is common, affecting 300 million people worldwide. ${ }^{1}$ The prevalence of asthma is increasing in Africa, Latin America, Eastern Europe, Asia, and the US, and especially among children. ${ }^{1}$ For example, the prevalence of asthma rose in the US by $14.8 \%$ in $<10$ years $(2001-2010) .{ }^{2}$ Suboptimal control is common. ${ }^{1}$ Frequent day and night time symptoms, missed work and school, exacerbations requiring urgent 
care, and the cost of medications are only some of the ways poorly controlled asthma affects individuals and their families. In calculating the overall patient impact of poorly controlled asthma, effects on work productivity, learning at school, activity levels, quality of sleep, disruption of and stress on family life, and other nonmedical financial burdens should also be considered. Approximately 346,000 deaths worldwide are attributed to asthma annually. ${ }^{1}$ Asthma-related deaths can be sudden. Most occur within 24 hours of the onset of symptoms and before many individuals seek or receive medical care; tragically, many deaths occur in otherwise healthy children, adolescents, and young adults and even in those with mild or moderate persistent asthma. ${ }^{3}$

Fortunately, effective therapies for asthma exist. Medications are usually inhaled, which limits systemic adverse effects. Long-term controller medicines taken daily decrease airway inflammation, prevent symptoms, and lower the frequency of exacerbations. Because of their relative safety and efficacy, inhaled corticosteroid (ICS) is currently recommended as first-line daily controller therapy for persistent asthma in treatment guidelines: the Global Initiative for Asthma ${ }^{1}$ and National Asthma Education and Prevention guidelines $^{4}$ (Table 1). For persistent asthma not controlled by low-dose ICS alone, a "step-up" in therapy by increasing to a moderate dose is currently preferred. But adding

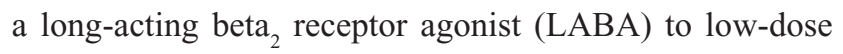
ICS therapy can be an alternative to increasing the dose of ICS. If asthma remains uncontrolled, the ICS regimen can be further titrated to high dose (with or without an LABA). Once an individual's asthma has been controlled for at least 3 months, a "step-down" to a lower ICS dose with an LABA or an ICS alone might be considered.

The GOAL study defined totally controlled asthma as the total absence of symptoms for at least 7-8 weeks. ${ }^{5}$ Results showed that the majority of patients with uncontrolled intermittent-to-severe persistent asthma could achieve and maintain control over 1 year, although this often takes higher ICS doses and/or combination therapy. More subjects on combination therapy achieved total control and became well controlled faster than those receiving ICS monotherapy.

Guidelines ${ }^{1,4}$ also recommend that all patients with asthma be prescribed a quick-relief inhaler. Quick-relief medicines are usually taken as needed to prevent symptoms when exposure of a known trigger is anticipated or to mitigate symptoms once they occur. The commonly prescribed quickrelief medicine is an inhaled short-acting beta ${ }_{2}$ receptor agonist like albuterol. However, a combination inhaler with a low-dose ICS (budesonide or beclomethasone) with

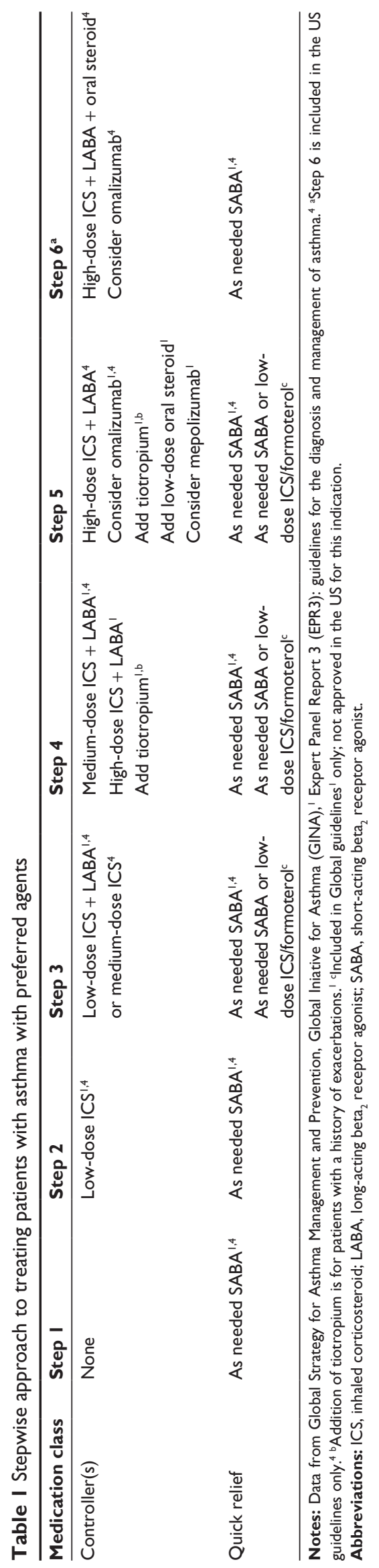


formoterol (an LABA) can be indicated as an alternative quick-relief medication in some countries. ${ }^{1}$

\section{Management issues}

Despite effective therapies, there are significant barriers to optimally controlling asthma. Health care system factors include under-assessment of asthma severity by providers with a resulting under-prescribing of controller medications. ${ }^{6,7}$ Lack of or inadequate health insurance can limit access to health care and medications. ${ }^{78}$ Currently, the cost of inhaled controller medications is negatively impacted by the lack of generic medications. Health care professionals should educate patients, especially on the value of taking controller medications daily to prevent symptoms. Correct inhaler device technique should be demonstrated by providers. ${ }^{1}$ Initial and repeated assessments are necessary for patients to initially demonstrate and maintain correct device technique to optimize drug delivery to and deposition in the lung. ${ }^{9}$ Although recommended by asthma guidelines, in one study, the provider demonstrated device technique to only $\sim 5 \%$ of children, and even fewer children were asked to show how they used their inhaler. ${ }^{10}$ Knowledge of correct device technique by providers (physicians, nurses, and respiratory therapists) has been documented to be inadequate. ${ }^{11}$ Lack of knowledge regarding device technique and briefness of office visits may contribute to the infrequent provision of asthma device education. Providers should seek and incorporate patient goals and views on therapy. ${ }^{7}$ At the same time, they should help all patients aspire to the maximal possible control of their asthma. ${ }^{5}$

Poverty is a major social factor contributing to poor asthma control, especially when it is concentrated in urban areas. ${ }^{8,12}$ Poor urban environments tend to have high allergen and irritant exposure (eg, diesel exhaust, dust mites, cockroach droppings, and deteriorating housing conditions). ${ }^{12}$ Other poverty-related factors are an increased prevalence of mental illness and less family support. ${ }^{12,13}$ The stress of limited financial resources to pay for medications and other medical care and the lack of transportation to keep medical appointments may further decrease one's ability to properly manage asthma. ${ }^{12,13}$

Patient-related factors also significantly contribute to poor asthma control. ${ }^{1}$ Non-adherence to controller therapy is historically common. An analysis of electronic claims data revealed that almost one-quarter of first-time controller prescriptions were never obtained or initiated (ie, primary non-adherence). ${ }^{14}$ Secondary non-adherence (ie, initiating therapy, but subsequently discontinuing it) is also problematic. More than $50 \%$ of American adults in one large study did not refill a controller medicine within 12 months of the initial prescription. ${ }^{15}$ Even if patients continue controller therapy, the prescribed regimen may not be correctly followed (ie, "improper use"). For example, medications may be used intermittently only when symptoms occur or used at a lower dose than prescribed. In one study, a third to one-half of subjects continuing controller medicines either underused them or did not follow the prescribed regimen..${ }^{14}$ In ten studies, the mean adherence rate with controller medications was only $48 \%$ of doses. ${ }^{15}$ Several studies indicated that children received only $30 \%-70 \%$ of prescribed doses. ${ }^{16}$ Adherence has been shown to be particularly problematic in low-income or ethnic minorities. ${ }^{16}$

Causes for poor controller adherence are likely multifactorial; many factors are intentional. ${ }^{1}$ In a telephone survey, ${ }^{17}$ individuals reported that they would more likely adhere to controller medicines if they perceived those medicines to be more effective at controlling symptoms, improve activity levels, act quickly with long duration, and to require less use of quick-relief medicines. Participants also expressed concerns about side effects and the overall risks of long-term exposure to medication. Patients also underestimate the severity of their asthma symptoms. ${ }^{7}$ The perception of asthma as an intermittent rather than a chronic disease may also discourage routinely taking daily controller medications. Inconvenience may be another factor; adherence has been noted to be higher in once-daily versus twice-daily regimens. ${ }^{1}$

Poor inhaler technique is common, ${ }^{10}$ which may contribute to patients' perception of medication ineffectiveness. Optimal technique for metered-dose inhalers (MDIs) versus dry powdered inhalers (DPIs) differs; technique even varies between assorted DPIs. ${ }^{10,11}$ So, a patient prescribed more than one type of inhaler device (eg, most quick-relief medications are MDIs, and many controllers are DPIs) will need to learn a different correct technique with each device. Multiple devices with different correct techniques could confuse individual patients. ${ }^{11}$ Health care professionals should be attentive to patient perceptions and careful to address preferences which might negatively impact adherence and therefore therapeutic efficacy.

\section{Treatment developments}

Due to the high cost of poorly controlled asthma, new and better therapies are constantly sought. One newer treatment option is inhaled tiotropium, a long-acting anticholinergic agent. Tiotropium is a common therapy for COPD, but has only recently been recommended for asthma not controlled 
by medium high-dose ICS plus LABA. ${ }^{1}$ Omalizumab, an anti-immunoglobulin E agent and mepolizumab, an IL-5 antagonist, have also been recommended for severe persistent asthma not controlled with high-dose ICS plus LABA combination therapy. ${ }^{1}$ Emerging therapies in pre-market trials and in varying stages of development target oligonucleotides, ${ }^{18}$ toll-like receptors, ${ }^{19}$ and tumor necrosis factor. ${ }^{20}$ The cost of omalizumab and these other evolving therapies will likely limit their use to severe persistent asthma not controlled by ICS plus LABA combination therapy.

As significantly more patients achieve control with combination therapy than with ICS therapy alone, ${ }^{5}$ ICS plus LABA combination therapy will likely remain the mainstay of treatment for many patients with persistent asthma. Various ICS-LABA combination products are available (Table 2). ${ }^{21-24}$ Based on the management issues discussed earlier, aspects to consider in selecting the best ICS plus LABA combination therapy for an individual patient should include a product which is perceived as effective and safe for long-term use, is well tolerated, is in a device that the individual is able to use correctly, the individual can afford, and has a convenient regimen. The remainder of this article focuses on comparing and contrasting a new product, fluticasone furoate plus vilanterol (FF-VI), to the other ICS-LABA combination products available focusing on these aspects likely to be important for patients.

\section{Pharmacology and pharmacokinetics of $\mathrm{FF}-\mathrm{VI}$}

Fluticasone furoate (FF) is a relatively new ICS. Its mechanism in asthma is presumed to be similar to other ICS. Corticosteroids modulate gene expression to decrease the production and release of cytokines and other mediators. By decreasing mediator release and eosinophil recruitment, airway inflammation is also decreased. ${ }^{4} \mathrm{FF}$ is a synthetic, lipophilic, trifluorinated corticosteroid. Unlike beclomethasone dipropionate and ciclesonide, FF is not a prodrug; FF does not require de-esterification for activation. Because FF rapidly reaches and slowly dissociates from the glucocorticoid receptor, it has a higher tissue and receptor affinity than other corticosteroids. These characteristics of FF also prolong the duration of its action, permit once-daily dosing, increase its potency, and lessen its systemic bioavailability compared to fluticasone proprionate (FP). ${ }^{25-27}$

Vilanterol (VI) is a relatively new LABA. Similar to other beta adrenergic agonists, its primary mechanism is activation of beta ${ }_{2}$ adrenergic receptors resulting in bronchodilation. Pharmacokinetically, VI has a similar onset
( $\sim 5$ minutes) to other LABAs like formoterol, arformoterol, and indacaterol, ${ }^{28-30}$ but a quicker onset than other LABAs such as salmeterol. ${ }^{28-30}$ VI has a half-life of 21 hours $^{24}$ allowing once-daily dosing. The duration of action of VI is more similar to indacaterol and olodaterol (ie, over 24 hours). Salmeterol or formoterol have significantly shorter durations of action requiring twice-daily dosing. ${ }^{28-30}$ It is hypothesized that VI's prolonged duration is due to its lipophilic, basic properties. These favor the formation of a drug depot in lipid bilayers of airway smooth muscle. Throughout the dosing interval, the drug leaks out from the depot to interact with the beta receptor.$^{30}$ Cytochrome P450 3A4 enzymes are the primary pathway to metabolize VI. The metabolites of VI are a thousand times less active than the parent compound. ${ }^{28}$ After inhalation, systemic VI concentrations are low due to limited absorption from the lung and rapid systemic metabolism. ${ }^{29,30}$

The new ICS-LABA product combining FF and VI is a logical one based on a similar duration of action and once-daily dosing. The product is available in two strengths (Table 2) of FF which allows a step-up or step-down titration of the ICS dose. Typical of other ICS-LABA combination products, the dose of VI is the same in both products as further increases in LABA dose usually do not provide significantly more bronchodilation. This combination is packaged in a relatively new DPI device, Ellipta ${ }^{\circledR}$.

\section{Efficacy of fluticasone-VI}

To identify clinical trials involving FF-VI, a PubMed and EMBASE search was performed in October 2015 using the MeSH terms "fluticasone", "vilanterol", and "asthma". Additional information was gathered from references cited in the identified publications, the manufacturer, package

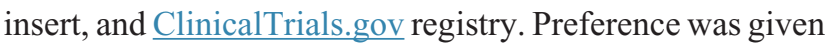
to randomized controlled clinical trials. Animal trials, trials for COPD, and non-English sources were excluded.

Trials establishing dosage ranges have shown that both the 100 and $200 \mu \mathrm{g}$ doses of FF improve lung function in subjects with persistent asthma versus placebo. ${ }^{31-33}$ Another study found that there was no difference in exacerbation rates between moderate dose of FP (250 $\mu \mathrm{g}$ twice daily) and low-to-moderate dose of FF (100 $\mu \mathrm{g}$ once daily). ${ }^{34}$ The combination of FF-VI has been shown to suppress the early asthmatic response, ${ }^{35}$ the late asthmatic response, and airway hyperresponsiveness up to 24 hours post-allergen provocation. ${ }^{36}$ Not surprisingly, combining VI with FF therapy further improves trough forced expiratory volume at 1 second $\left(\mathrm{FEV}_{1}\right)^{34,37}$ and decreases the risk of experiencing 


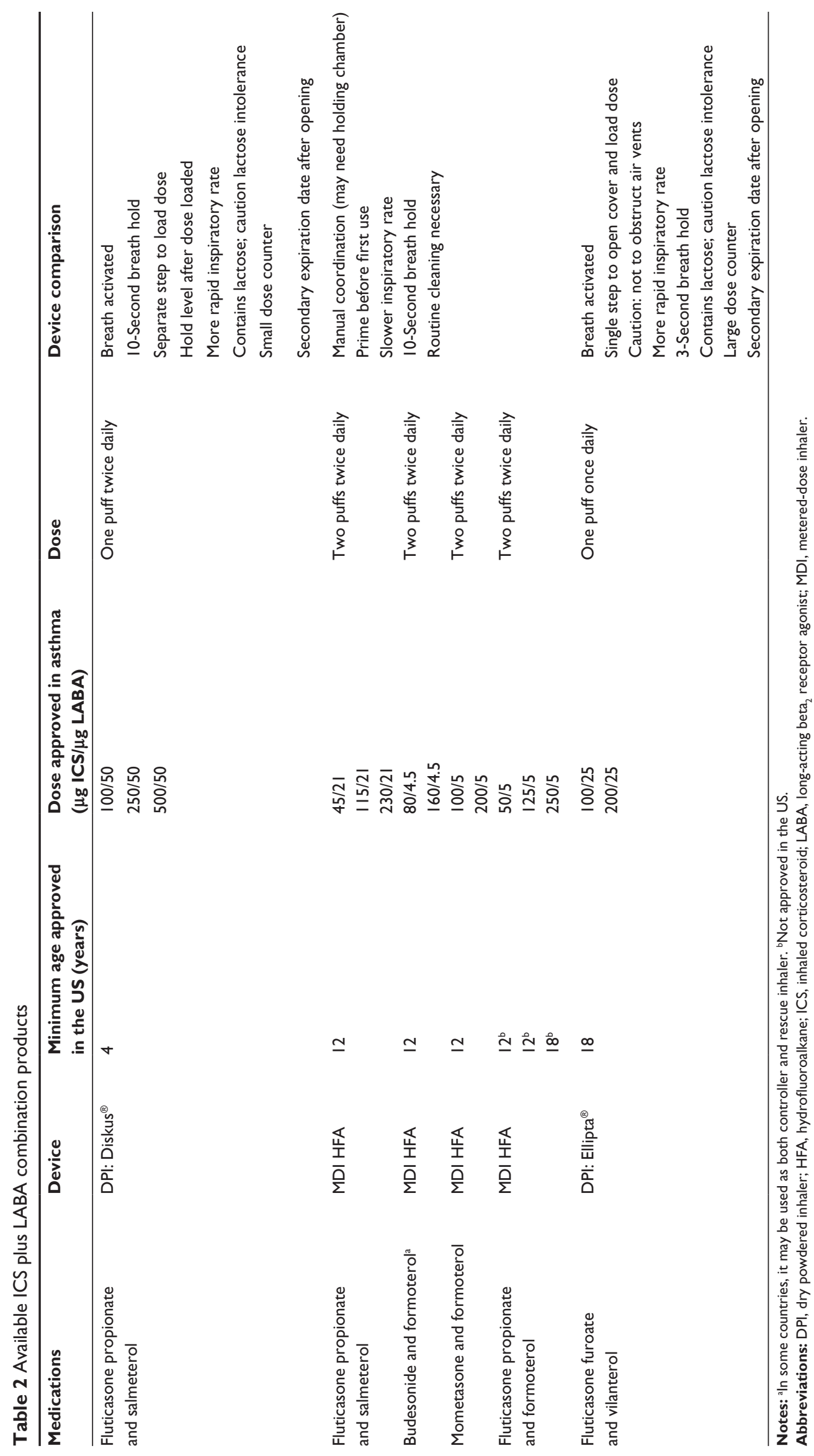


a severe asthma exacerbation. In a 52-week study, the adjusted probability of experiencing a severe exacerbation was reduced by $20 \%$ in subjects in the FF-VI group versus FF alone. In addition, the FF-VI combination significantly delayed the time to first severe asthma exacerbation. ${ }^{38}$

Our search only revealed one trial that compared FF-VI to another combination product, fluticasone propionatesalmeterol (FP-S) (Table 3$).{ }^{39}$ The primary end point of this Phase III, randomized, controlled, double-blinded, doubledummy, multicenter trial was the change from baseline in 0 - to 24-hour serial weighted mean $\mathrm{FEV}_{1}$ after 24 weeks of treatment. Secondary end points included scores on the Asthma Control Test ${ }^{\circledR}$ and a quality-of-life questionnaire, and unscheduled health care utilization rates. Results revealed an improvement from baseline in 0- to 24-hour $\mathrm{FEV}_{1}$ in both FF-VI (341 mL) and FP-S group $(377 \mathrm{~mL})$; however, the adjusted mean difference was not statistically significant. There was no difference in asthma exacerbation rates. The authors also reported that there were no key differences in any of the secondary end points between these two agents. This comparison trial was well designed. Although the primary end point was lung function, it also included some secondary end points that would likely be important to patients such as symptom scores and quality of life. Importantly, FF-VI appeared comparable clinically to another very well-studied combination product commonly used in clinical practice.

There are very limited data comparing FF-VI to other combination products. However, it appears reasonable based on the drugs' pharmacology and available clinical data to expect that this combination will have similar effects on lung function, and other clinical end points as other ICSLABA combination products. It would take more comparative studies of longer duration that include patient-oriented outcomes (eg, quality of life, symptoms scores) to ascertain if significant differences could be detected by patients that would result in preferences for one ICS-LABA combination product over another.

\section{Safety and tolerability of fluticasone-VI}

As previously mentioned, patient concerns regarding drug safety and overall drug exposure may affect adherence. Three trials were designed to specifically investigate potential safety of FF-VI (Table 4). ${ }^{40-42}$ The most commonly reported adverse drug reactions (ADRs) were headache, ${ }^{40,42}$ nasopharyngitis, ${ }^{40}$ and upper respiratory tract infections. ${ }^{40}$ Another study ${ }^{41}$ is of special interest because it was in children (5-11 years old). This study concluded that all reported ADRs were mild in intensity. None were deemed to be drug-related; the headache, upper respiratory tract infections, conjunctivitis, and sore throats were typical childhood illnesses. ${ }^{41}$ Unfortunately, risk of long-term ADRs such as growth delay and suppression of the hypothalamus-pituitary-adrenal (HPA) axis could not be assessed, as this was a relatively short trial $(<11$ weeks in duration).

Similarly, the most commonly reported ADRs in clinical trials were nasopharyngitis, headache, ${ }^{35,37,43}$ and oral candidiasis. ${ }^{34,35}$ In the trial by Woodcock et al which compared FF-VI to FP-S, ${ }^{39}$ the frequency and type of ADRs reported were similar to those reported earlier and were comparable between the two groups (Table 3).

In terms of long-term drug exposure, systemic effects of ICS therapy are dependent on the amount of drug orally absorbed and its pharmacokinetic and pharmacodynamic properties. As FF-VI has a high first-pass metabolism and limited systemic absorption at therapeutic doses, minimal long-term systemic ADRs would be anticipated. A short-term study found FF-VI to be non-inferior to placebo for serum

Table 3 Comparison of FF-VI to another ICS-LABA combination product

\begin{tabular}{|c|c|c|c|c|c|}
\hline \multirow[t]{2}{*}{ Study } & \multirow[t]{2}{*}{ Products (regimen) studied } & \multirow[t]{2}{*}{ End points } & \multicolumn{3}{|c|}{ Most common ADRs reported (\%) } \\
\hline & & & ADR & FF-VI & FP-S \\
\hline \multirow[t]{10}{*}{ Woodcock et al $\left.\right|^{39}$} & FF-VI ( $100 / 25 \mu \mathrm{g}$ once daily) versus & Primary & Nasopharyngitis & 53 & 49 \\
\hline & FP-S $(250 / 50 \mu \mathrm{g}$ twice daily) & Change in 0 - to 24-hour $\mathrm{FEV}_{\text {, }}$ & Headache & 34 & 41 \\
\hline & & $\mathrm{FF}-\mathrm{VI}(34 \mathrm{I} \mathrm{mL})$ versus FP-S & URTI & 26 & 16 \\
\hline & & $(377 \mathrm{~mL})(\mathrm{NS})$ & Cough & 15 & 13 \\
\hline & & & Sinusitis & 12 & 7 \\
\hline & & Secondary (all NS) & & & \\
\hline & & Exacerbation rates & & & \\
\hline & & ACT scores & & & \\
\hline & & QOL questionnaire scores & & & \\
\hline & & Unscheduled health care use & & & \\
\hline
\end{tabular}

Abbreviations: ACT, Asthma Control Test ${ }^{\circledR}$; ADR, adverse drug reaction; FEV , forced expiratory volume at I second; FF-VI, fluticasone furoate-vilanterol; FP-S, fluticasone propionate-salmeterol; ICS, inhaled corticosteroid; LABA, long-acting beta ${ }_{2}$ receptor agonist; NS, not significant; QOL, quality-of-life; URTI, upper respiratory tract infection. 
Table 4 Summary of data from FF-VI safety trials

\begin{tabular}{|c|c|c|c|c|c|c|}
\hline \multirow[t]{2}{*}{ Drugs studied } & \multirow{2}{*}{$\begin{array}{l}\text { Doses } \\
(\text { ICS } \mu \mathrm{g} / \mathrm{LABA} \mu \mathrm{g})\end{array}$} & \multirow[t]{2}{*}{ Duration of trial } & \multicolumn{4}{|c|}{ Common adverse effects reported (\%) } \\
\hline & & & ADR & FF-VI $100 / 25 \mu \mathrm{g}$ & FF-VI $200 / 25 \mu \mathrm{g}$ & FP $500 \mu \mathrm{g}$ \\
\hline \multirow[t]{2}{*}{$\mathrm{FF}-\mathrm{VI} \mathrm{I}^{40}$} & $100 / 25$ or $200 / 25$ & 52 weeks & Headache & 39 & 35 & 23 \\
\hline & once daily & & URTI & 34 & 30 & 18 \\
\hline \multirow[t]{5}{*}{ FP } & $500 \mu g$ twice daily & & Nasopharyngitis & 25 & 19 & 10 \\
\hline & & & Cough & 9 & 11 & 13 \\
\hline & & & Oral candidiasis & 15 & 13 & 3 \\
\hline & & & Sinusitis & 9 & 4 & 5 \\
\hline & & & ADR & FF-VI 100/25 $\mu \mathrm{g}$ & FF $100 \mu \mathrm{g}$ & \\
\hline $\mathrm{FF}-\mathrm{VI} \mathrm{I}^{4}$ & 100/25 once daily & I4-day initial & Headache & 1 & 0 & \\
\hline \multirow{5}{*}{$\mathrm{FF}$} & & therapy +7-day & URTI & 0 & I & \\
\hline & $100 \mu \mathrm{g}$ twice daily & wash-out + I4-day & Conjunctivitis & 1 & 0 & \\
\hline & & cross-over to & Bronchitis & I & 0 & \\
\hline & & other treatment & $\begin{array}{l}\text { Streptococcal } \\
\text { pharyngitis }\end{array}$ & I & 0 & \\
\hline & & & ADR & FF-VI 100/25 $\mu \mathrm{g}$ & FF-VI $200 / 25 \mu \mathrm{g}$ & \\
\hline \multirow[t]{6}{*}{$\mathrm{FF}-\mathrm{VI} \mathrm{I}^{42}$} & $100 / 25$ or $200 / 25$ & 42 days & Headache & 27 & 16 & \\
\hline & once daily & & Nasopharyngitis & 4 & 2 & \\
\hline & & & Sinus headache & 2 & 4 & \\
\hline & & & Cough & 0 & 0 & \\
\hline & & & Sinusitis & 4 & 0 & \\
\hline & & & $\begin{array}{l}\text { Oropharyngeal } \\
\text { candidiasis }\end{array}$ & 0 & 2 & \\
\hline
\end{tabular}

Note: Data from Busse WW et al, ${ }^{40}$ Oliver $\mathrm{A}$ et al, ${ }^{41}$ and Allen $\mathrm{A}$ et al. ${ }^{42}$

Abbreviations: ADR, adverse drug reaction; FF-VI, fluticasone furoate-vilanterol; FP, fluticasone propionate; FF, fluticasone furoate; ICS, inhaled corticosteroid; LABA, long-acting beta ${ }_{2}$ receptor agonist; URTI, upper respiratory tract infection.

cortisol levels after 42 days of treatment. ${ }^{42}$ A longer study (52 weeks) assessed urinary cortisol excretion (which might indicate HPA axis suppression) and ophthalmic changes such as intraocular pressure, changes in ocular appearance, and visual acuity. ${ }^{40}$ Adolescent and adult subjects (aged 12-73) were randomized into one of three groups: FF-VI 100/25 $\mu \mathrm{g}$ once daily, FF-VI 200/25 $\mu \mathrm{g}$ once daily, or FP $500 \mu \mathrm{g}$ twice daily. Subject-reported "ocular effects" were low and similar in frequency across the three groups; no differences were found between groups with regard to ophthalmic assessments. Utilizing intention-to-treat analysis, the majority of patients were found to have normal or no changes from baseline in their 24-hour free cortisol excretion at any time point after baseline. The trial comparing FF-VI to another ICS-LABA combination (FP-S) assessed 24-hour urinary cortisol both at baseline and at the end of 24-week treatment period. ${ }^{39}$ These authors found that patients in both FF-VI and FP-S groups had an increase in urinary cortisol excretion; however, the difference between groups was not statistically significant at week 24.

Like other ICS, FF appears well tolerated with similar common ADRs which are primarily local: oral candidiasis, dysphonia, upper respiratory tract infections, and throat irritation. ${ }^{4,24}$ Rinsing the mouth with water after use $e^{4,44}$ is recommended. Using the lowest dose required to control symptoms can help minimize or prevent these effects also. ${ }^{45}$ To limit the potential for systemic effects such as decreases in bone mineral density and resulting risk of osteoporosis and bone fracture, cataracts, or glaucoma, the lowest effective dose should be used, and a step-down in ICS dose should be made once asthma is controlled.

As a class, LABAs are usually well tolerated with the most common ADRs including sinus congestion, rhinitis, headache, and influenza. ${ }^{24}$ However, the Salmeterol Multicenter Asthma Research Trial in $2006^{46}$ raised concerns because of the unexpected increase in mortality seen with LABA therapy when combined with usual treatment for asthma. No increase in mortality was seen in the subset of subjects who self-reported as also taking an ICS at baseline. The analysis of this data subset is not conclusive. But one hypothesis for the increase in observed mortality was that salmeterol (without an ICS) in asthma may mask a worsening of lung inflammation rather than have a direct toxic effect. ${ }^{4}$ It is presumed at this time that the risk of asthma-related death is a class effect of LABAs. Therefore, currently all LABA products, whether individual or ICS-LABA combination 
products, have the same warning regarding the increased risk of asthma-related deaths.

Although there are limited data comparing the safety of various ICS-LABA combination products, it is a reasonable assumption that the safety of FF-VI is likely comparable to other available combination products. The most common ADR likely to concern patients would be thrush and dysphonia which are usually readily controlled or prevented. However, treatment can extend for decades after the initial diagnosis of asthma. So, more data would be helpful to assess FF's potential impact on other long-term ICS-related concerns such as on bone demineralization, cortisol, glaucoma, and cataracts. More data would be needed regarding the long-term effects of FF-VI on normal child growth and development prior to receiving an indication for treatment of asthma in children.

\section{Patient perspectives on combination inhalers and implications for adherence}

Use of a combination inhaler device is logical when ongoing ICS plus LABA therapy is necessary to control symptoms (Table 2 provides a list and comparison of available combination [ICS + LABA] products). As asthma regimens become more complex (eg, increased number of medications and/or number of doses per day), adherence tends to deteriorate. ${ }^{47}$ When used in a single device, ICS-LABA therapy may improve adherence rates based on claims data compared to administering the same two products in separate inhalers. ${ }^{7,47-49}$ Combination inhalers may also lower the need for quick-relief agents, ${ }^{48}$ lower frequency of asthma exacerbations, ${ }^{51}$ and reduce the risk of self-discontinuation of one of the medications. ${ }^{7}$ Another potential advantage of combination products is a lower patient cost as a result of one co-payment versus two. The UK asthma guidelines ${ }^{50}$ actually recommend the use of a combination device for patients who require both an ICS and an LABA medication. The US Food and Drug Administration has mandated that pediatric and adolescent patients must utilize a combination product when an LABA is needed. ${ }^{51}$

ICS-LABA combination devices are available as either an MDI with hydrofluoroalkane liquid propellant or a DPI without a propellant. Proper lung deposition of medication results from the interaction between the aerosol or dry powder formulation and the specific device used. ${ }^{7}$ For inhaled therapy to achieve the desired and achievable clinical benefits, patients need to be able to initially utilize the specific device correctly and be adherent with good device technique over time. ${ }^{52}$ As previously noted, there are significant differences in optimal technique between MDIs and DPIs and also between the various DPI devices. Devices of the available ICS-LABA products and some of the important device technique differences are listed in Table 2.

There are some trickier aspects to using MDIs correctly. MDIs usually require priming before first use to initially load a full dose into the metered-dose chamber. Priming may also be recommended if an MDI is not used for a period of days or weeks. The number of puffs to prime and exact period when re-priming becomes necessary is product specific. Failure to prime the MDI would result in a partial dose released for the first few activations. As controller medications are used each day, the lack of priming on first dose would be the concern for adherent patients. On the other hand, most DPIs like the Diskus ${ }^{\circledR}$ do not require priming. But each dose is manually loaded, and patients sometimes forget to load the dose. The Ellipta ${ }^{\circledR}$ device with FF-VI has the advantage over the Diskus ${ }^{\circledR}$ that opening the cover of the device also loads the dose. So as long as the Ellipta $^{\circledR}$ cover is completely opened and closed, the next dose should be fully loaded.

Typically, use of MDIs requires manual coordination between the device actuation and inhalation. Timing the breath either too early or too late in relation to actuation results in significant dose loss. Because the manual coordination required for optimal use of MDIs can be difficult for many patients, concurrent use of a holding chamber is often recommended. Holding chambers allow a slight pause between the time the patient presses down to actuate a dose and the time of inhalation. Holding chambers have the added advantage of decreasing the amount of ICS mouth deposition, lowering the incidence of thrush and dysphonia. But holding chambers add a slight expense and are less convenient to carry. DPIs use inspiratory force of the breath to disperse the fine drug powder (breath activated) and therefore require less coordination. ${ }^{50}$

Because DPIs are breath activated, a greater inspiratory flow rate is required to de-aggregate the drug powder into appropriate-sized particles to achieve optimal lung deposition. Usually, because of the propellant, MDIs require a slower inspiratory rate $(30-60 \mathrm{~L} / \mathrm{min})$ than DPIs $(60 \mathrm{~L} / \mathrm{min}$ or more). However, breathing in too quickly from an MDI could result in increased drug deposition in the mouth and back of the throat, increasing the potential of thrush and dysphonia with ICS therapy. The correct inspiratory rate is an important teaching point when instructing patients on device 
technique. Inability to generate an adequate inspiratory force is mainly a concern with very young children or those with very poor lung function. If it is suspected that a particular patient may not be able to generate sufficient inspiratory force to use a DPI correctly, testing the patient's inspiratory rate with an InCheck Dial ${ }^{\circledR}$ may be useful. ${ }^{53}$ A 2 Tone Trainer ${ }^{\circledR}$ can be helpful in teaching patients the slower inhalation rate optimal for MDIs. ${ }^{54}$ Other steps in device technique, such as exhaling away from the device prior to dose inhalation and completing a full deep breath, are similar and important for both DPIs and MDIs.

The maintenance of DPIs is simpler than MDIs. Wiping of the mouthpiece with a dry cloth (if wet) is all that is required. Routine cleaning of MDIs (and holding chambers) is recommended to maintain optimal particle size and for a complete dose release. In terms of storage, both MDIs and DPIs need to be protected from extremes of heat and cold; DPIs may be more sensitive to external moisture, which could cause the drug powder to clump. An advantage of MDIs is that they can continue to be used until the package's original expiration date. After opening, DPIs have a secondary expiration date. The Ellipta ${ }^{\circledR}$ has a slightly longer secondary expiration date than the Diskus ${ }^{\circledR}$. However, as most controller medications are packaged with a 30-day supply, the secondary expiration is primarily of concern only when controller therapy is temporarily interrupted or changed (eg, hospitalizations or titrating therapy up or down).

In designing the Ellipta ${ }^{\circledR}$, ease of use of the device was considered (Table 2). The technique requires fewer steps than the Diskus ${ }^{\circledR}$. The dosage counter window is larger. The Ellipta ${ }^{\circledR}$ requires a shorter breath holding after inhalation than other DPI and MDI devices. An advantage over the Diskus ${ }^{\circledR}$ is that the Ellipta ${ }^{\circledR}$ does not need to be held level after loading the dose. However, the Ellipta ${ }^{\circledR}$ does need to be held without obstructing the air outlets on the top. Like the other ICSLABA combination devices, the Ellipta ${ }^{\circledR}$ does not "lock out" to prevent continued use after it is empty. ${ }^{21}$ The formulation of both of these combination DPI products contains lactose, so an MDI device would be a better recommendation for the small number of patients with severe lactose intolerance.

Patient perceptions of the Ellipta ${ }^{\circledR}$ design were evaluated. A sub-analysis ${ }^{55}$ of three Phase III clinical trials assessed the ease of use of the Ellipta ${ }^{\circledR}$ by questionnaire. Subjects were asked to rate the usability of the DPI and how easy it was to determine remaining doses. The following ordinal scale was utilized: very easy, easy, neutral, difficult, and very difficult. Overall, $\sim 65 \%$ (640/987 patients) rated the Ellipta ${ }^{\circledR}$ as very easy to use, and $94 \%$ of patients reported it was easy or very easy to use. Only $1 \%$ ranked the Ellipta ${ }^{\circledR}$ as difficult or very difficult to use. Similarly, 74\% responded that it was very easy to determine remaining doses with the dose counter, and $95 \%$ ranked this as either easy or very easy. Less than $1 \%$ found this difficult or very difficult. After an initial device technique demonstration, subjects' technique was assessed at baseline, week 2, and week 4. After initial instruction, 95\% of subjects correctly demonstrated technique; $99 \%$ used the device correctly at week 2 and week 4 follow-up.

Other authors summarized qualitative interviews with subjects with asthma or COPD enrolled in clinical trials using the Ellipta ${ }^{\circledR}$ device. ${ }^{56}$ Participants reported high levels of satisfaction and a very positive experience with the Ellipta ${ }^{\circledR}$ device. Specific attributes cited included the simplicity of operation, visibility and interpretation of the dose counter, fit and feel of the mouthpiece, and design ergonomics. The ease of use of the Ellipta ${ }^{\circledR}$ device may boost patient satisfaction and overall confidence with using the device correctly.

These data on device technique and patient satisfaction are encouraging as there are much published data indicating that the device technique can be problematic. ${ }^{57}$ Whether data from trial participants will similarly translate into everyday clinical practice remains to be documented. None of the guidelines ${ }^{1,4,11}$ conclude that one inhalation device is significantly better (if used correctly) than another. So when selecting therapy and a specific delivery device for a particular patient, his/her device preference, ability to use the device correctly, ${ }^{52}$ and $\operatorname{cost}^{50}$ are important considerations. Regardless of the device selected, health care professionals should counsel every patient on the correct technique for that device, which includes a demonstration. Adequacy of the patient's technique should be assessed initially and at follow-up.

It has also been shown that shared decision making incorporating a patient's personal asthma goals and therapy preferences into a "negotiated" regimen can improve adherence to controller therapy. ${ }^{58}$ Other aspects of the FF-VI product may increase its acceptability to patients. It is available in combination in two ICS strengths with FF and in an FF alone product, which make it easy to step up or down on the regimen without having to change the device type. The efficacy of FF-VI is comparable regardless of whether the daily dose is scheduled in the morning or evening. ${ }^{43}$ Patients can be educated to use their combination product once daily at a time that is convenient for them which may improve patient acceptance. For patients who would like a single device 
(ie, use the same product as both their controller and quickrelief medication), another product may be best as FF-VI does not have an indication as a quick-relief medication.

The last consideration that is usually important to patients is cost. There are many variables that can influence cost including availability of insurance and amount of patient co-pay. Prices of medications can vary widely depending on geographic location, but ICS-LABA formulations tend to be very expensive if patients need to purchase the medication themselves. At this time, none of the combination products is available generically. However, Mylan ${ }^{59}$ has applied to produce a generic version of FP-S. If one or more generic ICS-LABA combinations become available, the cost savings could greatly favor the patient preference for a generic product.

\section{Conclusion}

Data indicate that FF-VI is likely equally safe and efficacious to other currently available ICS-LABA products. There are some initial, favorable data regarding the impact of FF-VI on asthma outcomes generally important to patients such as improvement of quality of life and symptom scores. More data are needed regarding the long-term safety and efficacy of FF-VI, especially in comparison to other combination products. However, the once-daily dosing, flexibility of dose timing, the design, and ease of use of the Ellipta ${ }^{\circledR}$ device are likely to be viewed favorably by patients compared to other available ICS-LABA combinations in other devices. But health care professionals should be familiar with the differences between respiratory devices and optimal technique in order to select an appropriate device and counsel patients on optimal technique for that device. The availability in the Ellipta ${ }^{\circledR}$ device of a range of ICS strengths, both as FF individually and in combination with VI, should simplify changes from the patient perspective when a step-up or step-down in therapy is required. One limitation is that the product's indication is reserved for adults at this time. Data to support a pediatric indication would be helpful. Should a generic version of an ICSLABA become available, cost will likely be an important consideration by patients.

However, many factors affect patient-specific acceptance of and adherence to therapy, which ultimately impacts therapeutic efficacy of ICS-LABA therapy. No product can be recommended as the preferred ICS-LABA product at this time; selecting an optimal ICS-LABA product for an individual patient is only possible after seeking input to explore the perception of asthma as a disease and various product options from that person's perspective. Regardless of ICS-LABA product chosen, it is important to provide device instruction and document the ability of the patient to use that device correctly.

\section{Disclosure}

The authors report no conflicts of interest in this work.

\section{References}

1. Global Strategy for Asthma Management and Prevention, Global Iniative for Asthma (GINA) 2016. Available from: http://ginasthma. org/2016-gina-report-global-strategy-for-asthma-management-andprevention/. Accessed April 25, 2016.

2. Centers for Disease Control and Prevention. Survey reveals growing national impact of asthma. Available from: http://www.cdc.gov/ media/releases/2012/p0515_asthma_impact.html. Accessed April 25, 2016.

3. O'Hallaren MT. Sudden death from asthma: is your patient at risk? Available from: http://www.medscape.org/viewarticle/512066_2. Accessed April 25, 2016.

4. Expert Panel Report 3 (EPR3): guidelines for the diagnosis and management of asthma. Available from: http://www.nhlbi.nih.gov/guidelines/ asthma/asthgdln.pdf. Accessed January 28, 2016.

5. Bateman ED, Boushe HA, Bousquet J, et al. Can guideline-defined asthma control be achieved? The Gaining Optimal Asthma Control Study. Am J Respir Crit Care Med. 2004;170:836-844.

6. Moonie S, Strunk RC, Crocker S, Curtis V, Schechtman K, Castro M. Community asthma program improves appropriate prescribing in moderate to severe asthma. J Asthma. 2005;42:281-289.

7. Scichilone N, Contino A, Figlioli GB, Paglino G, Bellia V. Patient perspectives in the management of asthma: improving patient outcomes through critical selection of treatment options. Patient Prefer Adherence. 2010;4:17-23.

8. Seid M, Opipari-Arrigan L, Gelhard LR, Varni JW, Driscoll K. Barriers to care questionnaire: reliability, validity, and responsiveness to change among parents of children with asthma. Acad Pediatr. 2009;9: 106-113.

9. Broeders M, Sanchis J, Levy ML, Crompton GK, Dekhuijzen PN. The ADMIT series: issues in inhalation therapy. 2) Improving technique and clinical effectiveness. Prim Care Respir J. 2009;18: 76-82.

10. Sleath B, Ayala GX, Gillete C, et al. Provider demonstration and assessment of child device technique during pediatric asthma visits. Pediatrics. 2011;127:643-648.

11. Dolovich MB, Ahrens RC, Hess DR. Device selection and outcomes of aerosol therapy: evidenced-based guidelines. Chest. 2005;127: $335-371$.

12. Laster N, Holsey CN, Shendell DG, McCarty FA, Celano M. Barriers to asthma management among urban families: caregiver and child perspectives. J Asthma. 2009;46:731-739.

13. Mansour ME, Lanphear BP, DeWitt TG. Barriers to asthma care in urban children: patient perspectives. Pediatrics. 2000;106: 512-519.

14. Fischer MA, Choudhry NK, Brill G, et al. Trouble getting started; predictors of primary medication nonadherence. Am J Med. 2011;124: 1081.e9-1081.e22.

15. Boulet LP, Vervloet D, Magar, Y, Foster JM. Adherence: the goal to control asthma. Clin Chest Med. 2012:33;405-417.

16. Klok T, Lubbers S, Kaptein AA, Brand PL. Every parent tells a store: why non-adherence may persist in children receiving guideline-based comprehensive asthma care. J Asthma. 2014;51:106-112. 
17. Bender BG, Long A, Parasuraman B, Tran ZV. Factors influencing patient decisions about the use of asthma controller medication. Ann Allergy Asthma Immunol. 2007;98:322-328.

18. Gupta GK, Agrawal DK. CpG oligodeoxynucleotides as TLR9 agonists. Biodrugs. 2010;24:225-235.

19. Meng L, He X, Zhu W, et al. TLR3 and TLR7 modulate IgE production in antigen induced pulmonary inflammation via influencing IL-4 expression in immune organs. PLoS One. 2011;6(2):e17252.

20. Stoll ML, Solomon DH, Batra KL, et al. TNF $\alpha$ inhibitors may improve asthma symptoms: a case series of 12 patients with rheumatoid arthritis and asthma. J Clin Rheumatol. 2009;15:198-200.

21. Breo [homepage on the Internet]. Available from: http://www.mybreo. com/asthma.html. Accessed January 28, 2016.

22. $\mathrm{emc}^{+}$. Fostair NEXThaler product information. Available from: http:// www.medicines.org.uk/emc/medicine/29177. Accessed January 21, 2016.

23. $\mathrm{emc}^{+}$. Fostair inhalation solution product information. Available from: http://www.medicines.org.uk/emc/medicine/21474. Accessed January 21, 2016.

24. Facts and Comparisons eAnswers. Available from: http://online. factsandcomparisons.com/MonoDisp.aspx?monoID=fandc-hcp 128 $79 \&$ quick $=650717 \% 7 \mathrm{c} 5 \&$ search $=650717 \% 7 \mathrm{c} 5 \&$ isstemmed $=$ True $\&$ NDCmapping=-1\&fromTop=true\#firstMatch. Accessed January 28, 2016

25. Salter M, Biggadike K, Matthews JL, et al. Pharmacologic properties of the enhanced-affinity glucocorticoid fluticasone furoate in vitro and in an in vivo model of respiratory inflammatory disease. Am J Physiol Lung Cell Mol Physiol. 2007;293:L660-L667.

26. Rossios C, To Y, To M, et al. Long acting fluticasone furoate has a superior pharmacological profile to fluticasone propionate in human respiratory cells. Eur J Pharmacol. 2011;670:244-251.

27. Allen A, Bareille PJ, Rousell VM. Fluticasone furoate, a novel inhaled corticosteroid, demonstrates prolonged lung absorption kinetics in man compared with inhaled fluticasone propionate. Clin Pharmacokinet 2013;52:37-42.

28. Malerba M, Radaeli A, Morjarioa JB. Therapeutic potential for novel ultra long-acting $\beta 2$-agonists in the management of COPD: biological and pharmacological aspects. Drug Discov Today. 2012;17: 496-504.

29. Bjerg A, Lundback B, Lotvall J. The future of combining inhaled drugs for COPD. Curr Opin Pharmacol. 2012;12:252-255.

30. Cazzola M, Page CP, Calzetta L, Matera MG. Pharmacology and therapeutics of bronchodilators. Pharmacol Rev. 2012;64: 450-504.

31. Bateman ED, Bleecker ER, Lotvall J, et al. Dose effect of once-daily fluticasone furoate in persistent asthma: a randomized trial. Respir Med. 2012;106:642-650.

32. Bleecker ER, Bateman ED, Busse WW, et al. Once-daily fluticasone furoate is efficacious in patients with symptomatic asthma on lowdose inhaled corticosteroids. Ann Allergy Asthma Immunol. 2012;109: 353-358.

33. Busse W, Bleecker ER, Bateman ED, et al. Fluticasone furoate demonstrates efficacy in patients with asthma symptomatic on medium doses of inhaled corticosteroid therapy: an 8-week, randomized, placebocontrolled trial. Thorax. 2012;67:35-41.

34. Lotvall J, Bleecker ER, Busse WW, et al. Efficacy and safety of fluticasone furoate $100 \mathrm{mcg}$ once-daily in patients with persistent asthma: a 24 week placebo and active-controlled randomized trial. Respir Med. 2014;108:41-49.

35. Oliver A, Quinn D, Goldfrad C, van Hecke B, Ayer J, Boyce M. Combined fluticasone furoate/vilanterol reduces decline in lung function following inhaled allergen $23 \mathrm{~h}$ after dosing in adult asthma: a randomized, controlled trial. Clin Transl Allergy. 2012;2:11-20.

36. Oliver A, Bjermer L, Quinn D, et al. Modulation of allergen-induced bronchoconstriction by fluticasone furoate and vilanterol alone or in combination. Allergy. 2013;68:1136-1142.
37. O'Byrne PM, Bleecker ER, Bateman ED, et al. Once-daily fluticasone furoate alone or combined with vilanterol in persistent asthma. Eur Respir J. 2014;43:773-782.

38. Bateman ED, O'Byrne PM, Busse WW, et al. Once-daily fluticasone furoate $(\mathrm{FF}) /$ vilanterol reduces risk of severe exacerbations in asthma versus FF alone. Thorax. 2014;69:312-319.

39. Woodcock A, Bleecker ER, Lotvall J, et al. Efficacy and safety of fluticasone furoate/vilanterol compared with fluticasone propionate/ salmeterol combination in adult and adolescent patients with persistent asthma. Chest. 2013;144:1222-1229.

40. Busse WW, O'Byrne PM, Bleecker ER, et al. Safety and tolerability of the novel inhaled corticosteroid fluticasone furoate in combination with the $\beta 2$ agonist vilanterol administered once daily for 52 weeks in patients $\geq 12$ years old with asthma: a randomized trial. Thorax. 2013; 68:513-520.

41. Oliver A, VanBuren S, Allen A, et al. Tolerability of fluticasone furoate/ vilanterol combination therapy in children aged 5 to 11 years with persistent asthma. Clin Ther. 2014;36:928-939.

42. Allen A, Schenkenberger I, Trivedi R, et al. Inhaled fluticasone furoate/ vilanterol dose not affect hypothalamic-pituitary-adrenal axis function in adolescent and adult asthma: randomized, double-blind, placebocontrolled study. Clin Respir J. 2013;7:397-406.

43. Kempsford RD, Oliver A, Bal J, Tombs L, Quinn D. The efficacy of once-daily fluticasone furoate/vilanterol in asthma is comparable with morning or evening dose. Respir Med. 2013;107:1873-1880.

44. Roland NJ, Bhalla RK, Earis J. The local side effects of inhaled corticosteroids. Current understanding and review of the literature. Chest. 2004; 126:213-219.

45. Lipworth BJ. Systemic adverse effects of inhaled corticosteroids. Arch Intern Med. 1999;159:941-955.

46. Nelson HS, Weiss ST, Bleecker ER, Yancey SW, Dorinsky PM. The Salmeterol Multicenter Asthma Research Trial: a comparison of usual pharmacotherapy for asthma or usual pharmacotherapy plus salmeterol. Chest. 2006;129:15-26.

47. Marceau C, Lemiere C, Berbiche D, Perreault S, Blais L. Persistence, adherence, and effectiveness of combination therapy among adult patients with asthma. J Allergy Clin Immunol. 2006;188:574-581.

48. Stoloff SW, Stempel DA, Meyer J, Stanford RH, Rosenzweig RJC. Improved refill persistence with fluticasone propionate and salmeterol in a single inhaler compared with other controller therapies. J Allergy Clin Immunol. 2004;113:245-251.

49. Stempel DA, Stoloff SW, Rosenzweig JRC, Stanford RH, Ryskina KL, Legorreta AP. Adherence to asthma controller medication regimens. Respir Med. 2005;99:1263-1267.

50. National Institute for Health and Care Excellence (NICE). Inhaled corticosteroids for the treatment of chronic asthma in adults and in children aged 12 years and over. 2008. Available from: guidance.nice. org/uk/ta138. Accessed September 11, 2015.

51. FDA.gov [homepage on the Internet]. http://www.fda.gov/Drugs/Drug Safety/PostmarketDrugSafetyInformationforPatientsandProviders/ ucm200776.html. Accessed January 28, 2016.

52. Nicolini G, Scichilon N, Bizzi A, Papi A, Fabbri LM. Beclomethasone/ formoterol fixed combination for the management of asthma: patient considerations. Ther Clin Risk Manag. 2008;4:855-864.

53. InCheck Dial [homepage on the Internet]. Available from: http:// www.clement-clarke.com/ProductInfo/InhalerTechniqueTraining/ InCheckDIAL.aspx. Accessed January 28, 2016.

54. 2Tone Trainer product information. Available from: http://2tonetrainer. net/. Accessed January 28, 2016.

55. Svedsater H, Jacques L, Goldfrad C, et al. Ease of use of ELLIPTA dry powder inhaler: data from three randomized controlled trials in patients with asthma. Primary Care Respir Med. 2014;24:14019.

56. Svedsater H, Dale P, Garrill K, Walker R, Woepse MW. Qualitative assessment of attributes and ease of use of the ELLIPTA ${ }^{\mathrm{TM}}$ dry powder inhaler for delivery of maintenance therapy for asthma and COPD. BMC Pulm Med. 2013;13:72. 
57. Papi A, Haughney J, Virchow JC, Roche N, Palkonen S, Price D. Inhaler devices for asthma: a call for action in a neglected field. Eur Respir J. 2011;37:982-985.

58. Wilson SR, Strub P, Buist AS, et al. Shared treatment decision making improves adherence and outcomes in poorly controlled asthma. Am J Respir Crit Care Med. 2010;181:566-577.
59. PRNewswire. Mylan confirms FDA submission of ANDA for Generic Advair Diskus. Available from: http://www.prnewswire.com/newsreleases/mylan-confirms-fda-submission-of-anda-for-generic-advairdiskus-300202571.html. Accessed January 28, 2016.

\section{Publish your work in this journal}

Patient Preference and Adherence is an international, peer-reviewed, open access journal that focuses on the growing importance of patient preference and adherence throughout the therapeutic continuum. Patient satisfaction, acceptability, quality of life, compliance, persistence and their role in developing new therapeutic modalities and compounds to optimize clinical outcomes for existing disease states are major areas of interest for the journal. This journal has been accepted for indexing on PubMed Central The manuscript management system is completely online and includes a very quick and fair peer-review system, which is all easy to use. Visit http://www. dovepress.com/testimonials.php to read real quotes from published authors.

Submit your manuscript here: http://www.dovepress.com/patient-preference-and-adherence-journal 